\title{
An elderly woman with severe enteritis mimicking infectious enteritis
}

\author{
Kazunori Nagashima ${ }^{1,2}$, Takashi Kato ${ }^{1}$, Taichi Kimura ${ }^{3}$, Kazuma Kishi ${ }^{1}$, Urara Baba $^{1}$ \\ ${ }^{1}$ Department of Gastroenterology and Hepatology, National Hospital Organization Hokkaido Medical Center, Sapporo; ${ }^{2}$ Department of \\ Gastroenterology and Hepatology, Faculty of Medicine and Graduate School of Medicine, Hokkaido University, Sapporo; ${ }^{3}$ Department of \\ Pathology, National Hospital Organization Hokkaido Medical Center, Sapporo, Japan
}

Question: An 80-year-old woman who was taking valsartan and amlodipine for hypertension, esomeprazole, apixaban and diltiazem for atrial fibrillation, and levothyroxine for chronic lymphocytic thyroiditis presented to our hospital with abdominal pain, vomiting and diarrhea. A blood test showed inflammation and malnutrition (white blood cell $4.9 \times 10^{3} / \mu \mathrm{L}$, hemoglobin $11.5 \mathrm{~g} / \mathrm{dL}$, platelet $17.2 \times 10^{4} / \mu \mathrm{L}$, total protein $5.5 \mathrm{~g} / \mathrm{dL}$, albumin $2.5 \mathrm{~g} / \mathrm{dL}$, aspartate aminotransferase $32 \mathrm{U} / \mathrm{L}$, alanine aminotransferase $19 \mathrm{U} / \mathrm{L}$, blood urea nitrogen $26.0 \mathrm{mg} / \mathrm{dL}, \mathrm{Cr}$ $1.10 \mathrm{mg} / \mathrm{dL}$, Na $134 \mathrm{mEq} / \mathrm{L}, \mathrm{K} 3.9 \mathrm{mEq} / \mathrm{L}$, and C-reactive pro- tein $20.9 \mathrm{mg} / \mathrm{dL}$ ). A stool culture showed commensal bacteria and a Clostridium difficile test was also negative. A computed tomography scan revealed severe inflammation of the small intestine, especially in the upper small intestine (Fig. A). We did single balloon enteroscopy and observed the duodenum and almost all of the upper small intestine. It showed erythema, mucosal fragility and villous atrophy enhancing mucosal fissures, and they looked like scalloped mucosa of celiac disease (Fig. B). Indigo carmine clearly revealed villous atrophy as shown in Fig. C. A pathological test of the small intestine
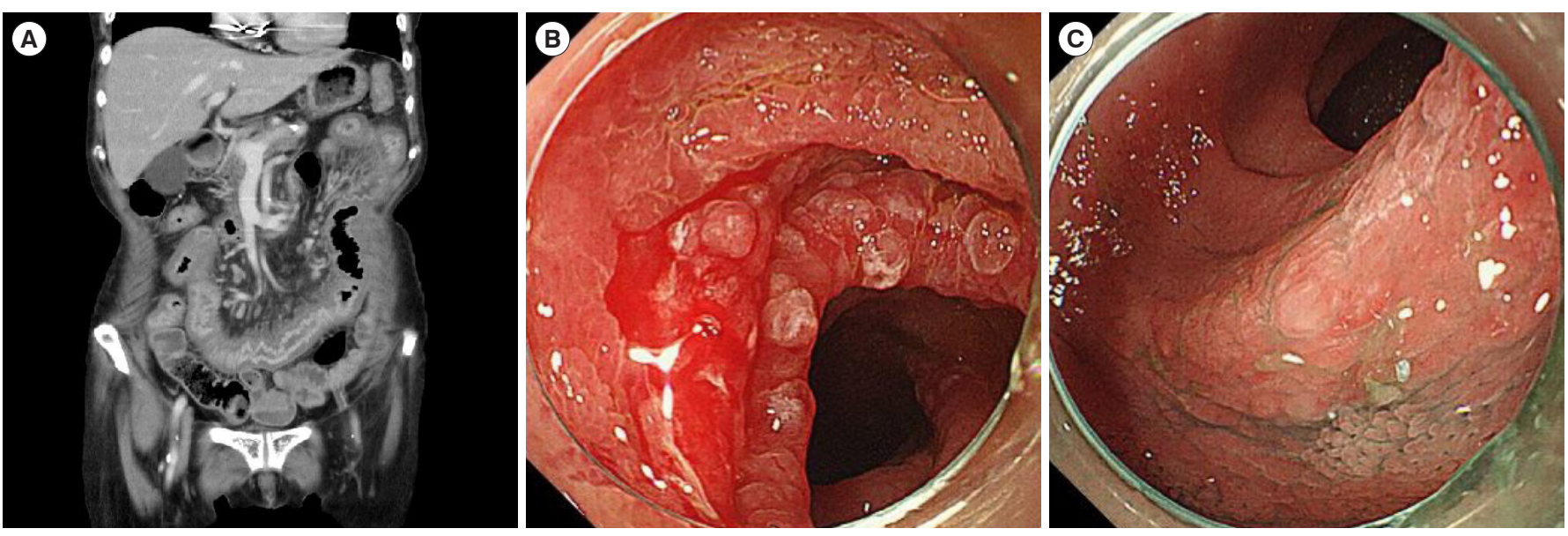

(Continued to the next page)

Received April 28, 2020. Revised May 6, 2020. Accepted May 10, 2020.

Correspondence to Kazunori Nagashima, Department of Gastroenterology and Hepatology, National Hospital Organization Hokkaido Medical Center, 5-7,

Yamanote, Nishi-ku, Sapporo 063-0005, Japan. Tel: +81-11-611-8111, Fax:+81-11-611-5820, E-mail: 1-tetsu@frontier.hokudai.ac.jp 


\section{(Continued)}

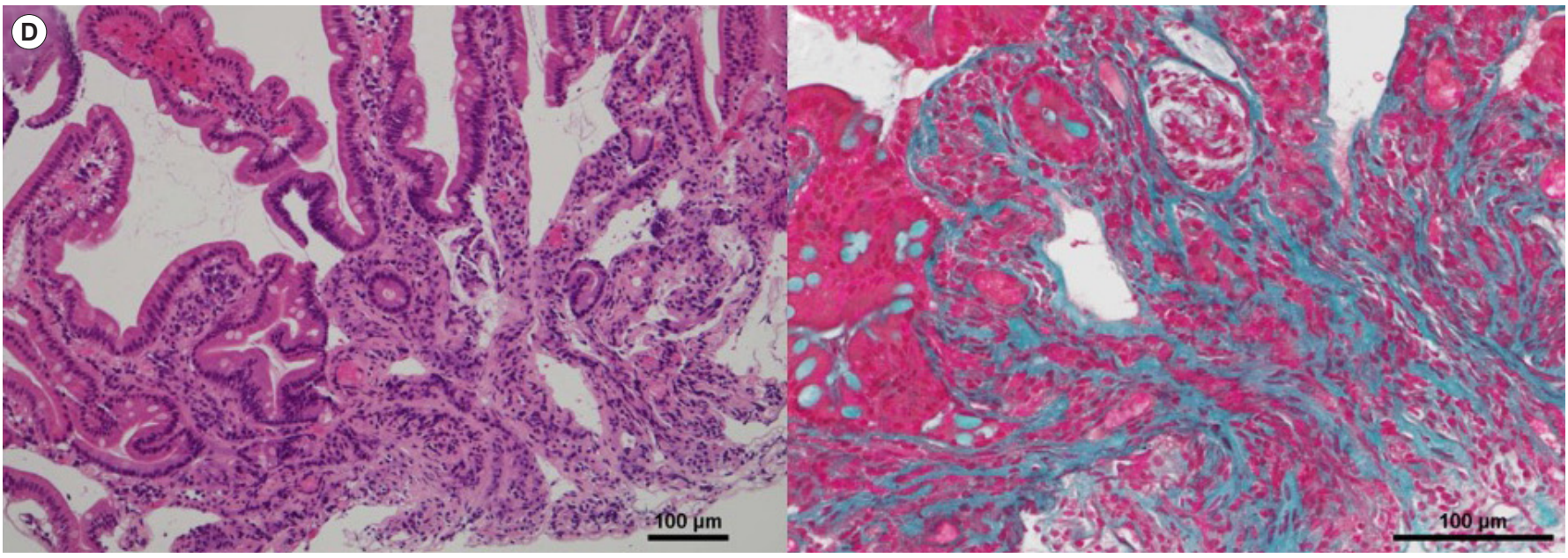

showed collagen deposition and intraepithelial lymphocytosis (Fig. D: left, H\&E; right, Elastica-Masson staining). At first, the patient was diagnosed with infectious enteritis and received conservative treatment with antibiotics (levofloxacin, ceftriaxone, tazobactam/piperacillin) for 3 weeks; however, the symptoms did not improve. Then, we did blood test again and it revealed negative for anti-transglutaminase and anti-endomysial antibodies. Therefore, we diagnosed her with a different enteritis, and began treating her with steroid therapy (prednisolone $30 \mathrm{mg}$ /day). She improved slightly; however, she got worse during steroid tapering. Written informed consent was obtained. What is the diagnosis?

\section{Answer to the Images: Valsartan-Associated Sprue-Like Enteropathy}

We eventually diagnosed the patient with valsartan-associated sprue-like enteropathy (VSE). She was taken off valsartan and began to improve. She was discharged from our hospital 19 days after valsartan discontinuation. Upon follow-up, she has not relapsed for 1 year. Her histocompatibility antigen (HLA) was HLA-DQ5/9.

Rubio-Tapia et al. ${ }^{1}$ reported about olmesartan induced spruelike enteropathy in 2012. It is thought that the pathogenesis involves olmesartan strongly blocking angiotensin II receptor type 1 on intestinal epithelial cells, which causes apoptosis of enterocytes and disorder of intestinal immune homeostasis. ${ }^{1,2}$ The enteropathy induces diarrhea, weight loss, vomiting, and abdominal pain among other symptoms. A negative blood test result for anti-transglutaminase or anti-endomysial antibodies and a positive result for villous atrophy, collagen depo- sition and intraepithelial lymphocytosis are helpful for a correct diagnosis. Rubio-Tapia et al. also reported that $81 \%$ of the patients in their study had HLA-DQ2 or HLA-DQ8. The patients received a gluten-free diet, steroid therapy, antibiotics and pancreatic enzymes for treatment; ${ }^{1}$ however, the discontinuation of the drug was effective for all of the patients. ${ }^{2}$

Lately, studies have suggested that some angiotensin 2 receptor blockers (ARBs) have induced enteropathy. The ratio of patients with VSE was $1.2 \%$ in patients with ARB-associated sprue-like enteropathy. ${ }^{3}$ To the best of our knowledge, there are only a few articles about VSE., ${ }^{4,5}$ Those cases, including our case, sometimes cause severe enteritis. Therefore, it is necessary to pay attention to this disease in cases with enteritis.

Our case did not improve with steroid therapy, and therefore discontinuation of the ARBs seemed to be the best treatment for the enteropathy. Also, our case exhibited severe enteritis and atypical HLA. When we see enteropathy in atypical cases, it is important to try discontinuing ARBs as a treatment option.

\section{ADDITIONAL INFORMATION}

\section{Funding Source}

The authors received no financial support for the research, authorship, and/or publication of this article.

\section{Conflict of Interest}

No potential conflict of interest relevant to this article was reported. 


\section{Author Contribution}

Data curation: Kimura T. Supervision: Baba U. Visualization: Kimura T, Kishi K. Writing - original draft: Nagashima K. Writing - review \& editing: Nagashima K, Kato T, Kimura T. Approval of final manuscript: all authors: all authors.

\section{ORCID}

Nagashima K https://orcid.org/0000-0003-0528-0390

Kato T

Kimura T https://orcid.org/0000-0003-4430-9678

Kishi K https://orcid.org/0000-0002-4084-1934

Baba U https://orcid.org/0000-0001-6610-8434 https://orcid.org/0000-0003-0745-6302

\section{REFERENCES}

1. Rubio-Tapia A, Herman ML, Ludvigsson JF, et al. Severe spru- elike enteropathy associated with olmesartan. Mayo Clin Proc 2012;87:732-738.

2. Ianiro G, Bibbò S, Montalto M, Ricci R, Gasbarrini A, Cammarota G. Systematic review: sprue-like enteropathy associated with olmesartan. Aliment Pharmacol Ther 2014;40:16-23.

3. Kamal A, Fain C, Park A, et al. Angiotensin II receptor blockers and gastrointestinal adverse events of resembling spruelike enteropathy: a systematic review. Gastroenterol Rep (Oxf) 2019;7:162-167.

4. Herman ML, Rubio-Tapia A, Wu TT, Murray JA. A case of severe sprue-like enteropathy associated with valsartan. ACG Case Rep J 2015;2:92-94.

5. Soldera J, Salgado K. Gastrointerestinal: valsartan induced sprue-like enteropathy. J Gastroenterol Hepatol 2020;35:1262. 